\title{
FERRAMENTAS PARA UMA PSICOLOGIA SOCIAL
}

\author{
Rafael Diehl \\ Cleci Maraschin\# \\ Jaqueline Tittoni"
}

\begin{abstract}
RESUMO. Este texto se propõe apresentar e discutir ferramentas de intervenção para o trabalho do psicólogo social engendradas em um espaço de intervenção e supervisão em estágio acadêmico de Psicologia Social. Para isso, busca problematizar a política e a ética das ações dessa psicologia, considerando sua constituição dentro de um contexto histórico e político, além de relacioná-las com as ferramentas elaboradas na prática e no espaço de supervisão. O escrever, o olhar e o percorrer são as ferramentas discutidas neste artigo, as quais se apresentam como constitutivas de uma posição autoral perante os desafios encontrados na experiência do estágio, através da assunção das condições políticas e éticas que possibilitam tal lugar.
\end{abstract}

Palavras-chave: psicologia social, estágio de psicologia social, ferramentas de intervenção.

\section{TOOLS FOR A TYPE OF SOCIAL PSYCHOLOGY}

\begin{abstract}
This paper presents and discusses intervention tools for working as a social psychologist, which are engendered in a space of intervention and supervision, in Social Psychology training or internships. Bearing that in mind, it raises questions on the policies and ethics of the actions concerning such psychology, considering its constitution within a historical and political context, besides relating them with the tools elaborated in the practice and in the supervision space. Writing, perceiving with unfamiliarity and roaming are the tools discussed in this paper, and such tools present themselves as constituent of an authorship position, when facing the challenges regarding the experience of trainee or internship, through political and ethical conditions that can make that position possible.
\end{abstract}

Key words: Social psychology, social psychology internship/training, intervention tools.

\section{HERRAMIENTAS PARA UNA PSICOLOGÍA SOCIAL}

RESUMEN. Este texto propone presentar y discutir herramientas de intervención para el trabajo del psicólogo social engendradas en un espacio de intervención y supervisión en práctica académica de Psicología Social. Para eso, busca problematizar la política y la ética de las acciones de esa psicología, considerando su constitución dentro de un contexto histórico y político, además de relacionarlas a las herramientas elaboradas en la práctica y en el espacio de supervisión. El escribir, el mirar y el recorrer son las herramientas discutidas en este artículo, las cuales se presentan como constitutivas de una posición relativa al autor ante los desafíos encontrados en la práctica, a través de la premisa que las condiciones políticas y éticas hacen eso posible.

Palabras-clave: psicología social; práctica en psicología social; herramientas de intervención goce.

Em 1997 iniciou-se no Departamento de Psicologia Social e Institucional do Instituto de Psicologia da UFRGS uma nova experiência de estágio, denominada Estágio em Psicologia Social. A
Constituição de 1988 tinha quase uma década e algumas transformações já se insinuavam nas políticas públicas: as experiências de organização de redes interinstitucionais unindo os campos da saúde e da

* Psicólogo. Mestrando do Pós Graduação em Psicologia Social e Institucional UFRGS.

\# Doutora. Professora do Programa de Pós-Graduação em Psicologia Social e Institucional e do Instituto de Psicologia da Universidade Federal do Rio Grande do Sul-UFRGS.

II Doutora. Professora do Programa de Pós-Graduação em Psicologia Social e Institucional e do Instituto de Psicologia da Universidade Federal do Rio Grande do Sul-UFRGS. 
educação; os princípios do SUS; o projeto da reforma antimanicomial; a escola inclusiva. Tais propostas questionavam antigas fronteiras tradicionais na psicologia - clínica, organizacional e escolar -, provocando o repensar da própria formação acadêmica. Aliados a essa circunstância, os processos de municipalização da saúde oportunizaram a abertura de vários concursos públicos em diversas cidades para a contratação de psicólogos. Os psicólogos recémcontratados viam-se diante do desafio de produzir articulações entre as "psicologias", uma vez que em muitas cidades pequenas o psicólogo era o único profissional da área no município.

A universidade, responsável pela formação profissional e pela construção teórica e metodológica de ferramentas para a intervenção, não pode ficar alheia a essas transformações. Alguns trabalhos já apontam nessa direção. A formação do psicólogo no sentido de sua implicação com os acontecimentos da cidade e a organização da sociedade foi problematizada por Baptista (2000) como uma questão urgente a ser pensada para além dos muros da academia. Outros trabalhos na área (Paparelli, 2005; Silva, Oliveira \& Franco, 1998) também apontam a importância de uma abertura para as questões políticas da organização de serviços públicos e da implicação dos estudantes com questões relativas ao contexto social.

Assim, este estágio foi projetado como um desafio para produzir uma formação que articulasse os temas de saúde, educação e trabalho a partir da problematização da implicação política e ética do fazer dos psicólogos em formação (Maraschin \& Tittoni, 2002; Scisleski, Maraschin \& Tittoni, 2006).

O presente artigo é fruto da reflexão de uma dessas experiências de estágio, a qual se desenvolveu no Projeto Saúde em Creches, da Secretaria Municipal de Saúde de Porto Alegre, no período de 2003-2004. A intervenção nos estabelecimentos de educação infantil conveniados com a prefeitura era feita por meio de equipes de estagiários multidisciplinares, coordenadas por uma gerência distrital de saúde e uma supervisão específica de cada área do conhecimento. Estagiários de psicologia, enfermagem, odontologia, medicina e assistência social visitavam regularmente as creches, buscando realizar um trabalho articulado. O Projeto Saúde em Creches objetivava estabelecer uma rede de prevenção e articulação com a atenção básica à saúde. As atividades programadas para os estagiários incluíam não só o acompanhamento das atividades nas creches, mas também ações com os pais e educadores e a construção de uma interlocução com o serviço de saúde mais próximo, no sentido de estabelecer um prolongamento deste serviço nestes espaços considerados estratégicos para ações no âmbito da saúde pública. O campo específico do projeto já anunciava possibilidades de intervenção e de reflexão caras à proposta do estágio. Entre elas podemse destacar: a busca de uma parceria entre a secretaria e as creches conveniadas; a organização do trabalho através de equipes multiprofissionais de estagiários; a viabilização de processos de formação e capacitação em serviço e a tentativa de articulação de uma rede da qual poderiam participar as instituições conveniadas (famílias, comunidade, postos de saúde, projetos sociais).

A proposta de estágio, pensada a partir do enfoque da psicologia social, trouxe para o estagiário e as supervisoras questionamentos e desafios que se constituíram em motores de um processo de mudança. Desse processo resultou o delineamento de ferramentas de cunho teórico-metodológico para intervenção que foram se tornando operativas durante o período de vivência do estágio.

Neste artigo, além de caracterizar as ferramentas forjadas na prática do estágio e da supervisão, pretendemos discutir suas implicações éticas e políticas. Para tornar operativos conceitos e metodologias, de maneira a garantir consistência e resolutividade à intervenção em psicologia social, torna-se necessário, de início, esclarecer a que saberes e práticas nos referimos, uma vez que a palavra Psicologia tem ganho muitas adendas, como forma de distinção entre os próprios saberes e as práticas. Cabe ressaltar que ao nos referirmos a uma psicologia social estamos delimitando um modo de saber-fazer-operar que engendra simultaneamente um objeto $\mathrm{e}$ modalidades de ação prática que, ao serem postos em ação, repercutem no próprio plano conceitual.

Assim, trabalhamos neste texto com uma perspectiva de psicologia social em ação referida não somente ao campo de atuação, mas como um conjunto de pressupostos epistemológicos e teóricos decorrentes de uma produção de conhecimento que se efetua como uma travessia entre dois lugares: o local das experiências irredutíveis do campo do estágio e o espaço de supervisão no qual se constitui um outro plano de construção da experiência e que também se constitui como prática de formação - passagem esta que se modula pela constituição política e pela contextualização histórica das produções de saberes e práticas envolvidas no trabalho do psicólogo.

Em um primeiro momento discutiremos alguns dos movimentos que tornaram possível articular e constituir uma relação entre um certo modo de pensar a relação sujeito-sociedade. Em um segundo 
momento, discutiremos os modos como as ferramentas foram engendradas entre o contexto da experiência no campo de estágio e das interlocuções e outras formas de visualização no espaço de supervisão. Por fím, apresentamos as ferramentas produzidas e presentes tanto nas intervenções nos locais de estágio como no espaço da supervisão, onde, por um processo contínuo de formação, elas se engendraram não em uma linearidade preestabelecida, mas como operadores presentes durante todo o processo.

\section{UMA PSICOLOGIA SOCIAL}

Para Ibáñes (1993), a pergunta sobre a dimensão política da psicologia social é uma falsa questão, pois parte do pressuposto da separação entre uma esfera política e um saber sobre ela. Para ele, as ciências sociais são implicitamente políticas, pois não se constituem numa exterioridade em relação aos objetos sobre os quais teorizam e nos quais intervêm. Ao contrário, são marcadas por uma reflexividade em relação ao seu objeto de estudo, pois o trabalho investigativo modifica a realidade social. Podemos evocar aqui situações nas quais o saber psi é chamado para produzir sujeitos necessários ou adaptados a uma certa configuração do social, como, por exemplo, na atualidade, sujeitos competentes e flexíveis para um liberalismo de mercado.

As intervenções do psicólogo estão sempre implicadas com uma ou mais posições de saber. Considerar que o saber da Psicologia não se constitui numa exterioridade em relação às produções sociais e históricas atreladas aos jogos de verdade conduz a aceitar que a pergunta pela dimensão política torna-se ainda mais crucial. Tomar como problema a dimensão política é tarefa de uma psicologia que assume seu fazer como constitutivo de seus objetos de conhecimento.

O pensamento liberal forja uma separação entre o econômico e o político, ao priorizar os interesses da propriedade e do capital. Assumir a responsabilidade pelas configurações que estas dimensões engendram na atualidade, seja pela via de um neoliberalismo individualizante que produz uma sensação de mérito e fracasso pessoal, seja pelo desvio das questões políticas para uma esfera apenas representativa, constitui-se em campo de problematização para o psicólogo. Essas configurações fazem parte do trabalho de intervenção e exigem uma apropriação da dimensão dos tensionamentos políticos de uma dada sociedade. Se deixadas de lado, podem servir de fomento para práticas docilizantes e mantenedoras de relações de poder com tendência à dominação.
Entendemos política como campo de táticas e estratégias em relações de poder onde o que está em questão é o governo de si e dos outros (Foucault, 1994). Tomar a dimensão política como problema envolve abandonar uma idéia de poder centralizado, assumido na atualidade pelo Estado como esfera distante de nosso cotidiano. $\mathrm{Na}$ operação da representatividade perdemos o entendimento da política como campo de confronto entre estratégias e programas de convivência no coletivo. Trazer a dimensão das discussões políticas para uma racionalidade prática (Ibáñes, 1993) passa a ser tarefa dessa psicologia social, na medida em que abandona um ideal de racionalidade científica que se configura epistemologicamente na manutenção de dualismos como os do sujeito e objeto, do local e global, do saber científico e senso comum. O fato de considerar a dimensão do político como campo de lutas e de estratégias para a constituição de um espaço possível para a convivência em um coletivo de singularidades irredutíveis faz com que essas dualidades possam ser questionadas com a configuração de outras fronteiras e diferenças.

Ao se assumir esta posição de desnaturalização dos campos de saber, faz-se necessário também encarar o social como problema, assim como proposto por Silva (2004): ao invés de tomá-lo como evidência, coloca-se o trabalho de se fazer uma genealogia do surgimento deste campo como resultado de um conjunto de práticas humanas. Dessa forma, é a partir de uma dada configuração do social, entendida como "superfície de inscrição de um conjunto de práticas que adquirem uma relativa consistência em um determinado momento" (Silva, 2004, p.15), que certas formas de relações ganham maior visibilidade. É nessa contingência que devemos colocar esta psicologia social, não tomada como uma nova área empírica de atuação do psicólogo, que estaria assim em ação no "social" - mesmo levando em consideração as condições em que este campo se constitui mas como indicativa de um posicionamento epistemológico e ético. Caso não haja essa diferença, toda psicologia seria social, já que nenhuma refuta a socialização, ou mesmo a interação, como fatores contextuais de seus objetos de análise e de intervenção. A especificidade do trabalho que aqui estamos definindo como um certo modo de fazer psicologia social se efetiva mais pelo posicionamento político, no sentido foucaultiano, do que pela circunscrição de lugar de atuação.

Questionar como um campo de saber foi produzido, considerando as circunstâncias históricas de sua emergência e os condicionantes de sua permanência, faz parte do trabalho de quem se dedica 
a essa psicologia social. Assumir uma posição de saber frente a outros, ao invés de posição confortável, é desafio para a produção de encontros com diferenças. Nessa perspectiva, a produção de problemas - antes que sua solução - assume importância crucial, na medida em que as problematizações postas diante de acontecimentos já naturalizados produzem deslocamentos por vezes desconcertantes, que abrem possibilidades de sentido, ações e modos de vida antes impensáveis.

Numa época em que a dimensão econômica assume proporções dominadoras através da lógica neoliberal e o político se resume a decisões da ordem do Estado ou sinônimo de corrupção, pensar o social não é apenas habitar o hiato indicado por Castel (1998). Trata-se de olhar como se fosse a primeira vez para tudo isso que construímos e em que estamos imersos, não de forma anárquica, mas guiados pelos pressupostos éticos que apontem para a possibilidade de habitarmos um espaço mais justo, onde o saber não sirva apenas para a dominação e manutenção do status quo.

A dimensão política e ética da problematização de circunstâncias dadas como naturais no campo da prática constituiu-se em uma posição a partir da qual foi possível forjar algumas das ferramentas de intervenção da prática do estágio.

\section{DAS FERRAMENTAS CONSTRUIIDAS NA PRÁTICA}

A experiência do estágio no projeto Saúde em Creches registrada em diários de campo e a interlocução na supervisão constituíram uma metodologia de produção de conhecimentos e de práticas recursivas que permitiu uma experimentação ativa de ação e reflexão sobre a ação. Nesse processo algumas ferramentas se delinearam no percurso do estagiário pelo campo, como instrumentos que ganhavam forma conforme a jornada. Categorias delineadas na intensidade da experiência e geridas com o papel fundamental da supervisão são apresentadas aqui na ordem em que foram aparecendo, seja pela forma do entendimento seja pela característica do trabalho no campo. Cabe ressaltar que, não obstante essa distinção na escrita, as ferramentas estão sutilmente imbricadas umas com as outras, como uma pequena rede potencialmente utilizável na prática da intervenção e da formação de diversas formas e conexões.

A articulação entre o espaço de supervisão e o campo de experiências do estágio poderia ser analisada conforme os conceitos de centro de cálculo e de periferia utilizados por Latour (2004) em sua análise dos modos operativos e constitutivos da ciência. Segundo o autor, a ciência se produz em uma rede na qual circulam inscrições forjadas a partir de um espaço de periferia - o local da experiência de campo - para o centro de cálculo, que se constitui como um espaço de transformação onde essas inscrições passam a ser comparáveis através da constituição de transformações que as tornam comensuráveis. Desta forma, quando as inscrições podem ser postas em relação nesse centro de cálculo, elas perdem a singularidade de sua existência em seu habitat natural, mas ganham na possibilidade de novas relações que podem ser feitas, enriquecendo a experiência e transformando um possível retorno ao espaço de campo.

Assim, podemos tomar emprestado esse modo operativo para pensar o espaço de supervisão como uma espécie de centro de cálculo. Ele se constitui em um lócus de visualização diferenciado do campo de estágio, onde novas formas de relação podem ser experimentadas, as quais constituem uma intervenção no modo de operar em campo, pois a experimentação da supervisão transforma a relação com o campo de estágio.

As ferramentas que operamos foram se delineando tanto na forma de orientação das supervisoras agenciando um acoplamento entre a experiência do estágio e o campo teórico e metodológico de formação do psicólogo - como durante a intervenção. O estar em campo era não só uma experimentação de teorias na prática, mas uma abertura a possibilidades na qual o corpo do estagiário tornava-se suporte de vivências em que era possível a inscrição de outras formas de operar com a realidade, tensionadas pela maneira específica como os relatos eram trazidos para a supervisão, gerando um efeito recursivo sobre as ações no campo de estágio.

A supervisão funciona, assim, estabelecendo outro campo de experimentação, no sentido de uma central de cálculos, onde as inscrições trabalhadas a partir da leitura do diário de campo compõem uma rede de conversações que tensiona e problematiza as inscrições de forma a produzir uma nova configuração. Essa nova configuração não busca cercear a experiência, mas relançar as inscrições como ingredientes de uma transformação que tinha como ponto central a própria constituição de um ser estagiário-psicólogo, possibilitando sua ação através do pensamento e sua aplicação no campo da intervenção. Ao narrar suas experiências, os estagiários não as transmitiam para outros a fim de adequá-las a uma certa teoria, mas eram instigados a 
suspender formas automáticas de delimitar a realidade suposta no campo de estágio. Desta forma, estas ferramentas operadoras do material vivenciado se constituíram em um conjunto de experiências em que a vivência - ao mesmo tempo angustiante e surpreendente - produzida no encontro com diferenças transformava-se em desafios ao pensamento, não através da cristalização em certa forma teórica - onde muitas vezes a angústia pode diminuir, como também o podem os limites para a alteridade - mas como desafios lançados ao modo de estar no mundo que delinearam nesta experiência as ferramentas que apresentamos a seguir.

As ferramentas são forjadas na experimentação de uma psicologia social configuradora de um modo de formação e supervisão em que a experiência do estágio não é vista como campo de delimitações para a teoria, mas constitui, junto com a supervisão, o exercício de uma política e uma ética da ação. Essa posição, como se comentou anteriormente, instiga à desnaturalização daquilo que enxergamos e do que conseguimos simbolizar a respeito de nós mesmos e do mundo, produzindo mudanças importantes nos modos de habitar os lugares possibilitados pela escolha da psicologia como formação profissional.

\section{ESCREVER}

A experimentação da escrita com o diário de campo possibilitou uma forma de distanciamento e de deslocamento da posição perante a experiência que se tornou parte importante da constituição do modo de ser estagiário, uma vez que se constituiu como ferramenta de tensionamento da experiência, além de tecnologia para os momentos de angústia, ou mesmo de euforia, produzidos pelo contato com os locais do estágio. Servindo como espaço de produção de inscrições (entendidas como tecnologia de produção de novas experiências, e não como transportadoras de idéias), a escrita se constitui em um campo importante no processo de formação, pois possibilita uma forma de constituição de si permeada pela intensidade da experiência e da experimentação de sua alteridade no texto lido $a$ posteriori, produzindo uma interlocução subjetiva que auxilia na exposição objetiva para o grupo da supervisão.

Em seguida, um trecho do diário de campo em que estes movimentos tiveram sua manifestação mais visceral e no qual a angústia pode encontrar outras formas de manifestação:
O ônibus lotado me expulsa para fora e paro diante do hospital onde terei uma consulta. Adentro o saguão belo, limpo e vazio e penso comigo mesmo que nesta cidade as coisas são bem melhores. Úmido engano, pois a entrada é pela emergência ao lado e pessoas se avolumam como os pingos de chuva lá fora. Mal-entendidos me lançam depois de horas atrás do meu lugar em uma fila invisível, mas acabo desistindo e saio frustrado para esperar o ônibus. Muitos litros depois, sento-me à janela, mas o vidro embaçado turva minha visão das áreas industriais, presentes e futuras, onde circulam operários crentes talvez no progresso industrial. Passam paisagens de belas casas e belas misérias, misturadas à água da chuva que abre caminho assim como o ônibus por ruas estreitas, que mostram construções curiosas e criativas escondidas no pequeno centro da periferia. Engulo um pedaço de torta na esperança de elevar meu humor, e o ambiente da lancheria parece estrangeiro quando comparado com as imagens da minha mente. Saio às pressas para não perder o ônibus circular que, por só passar na borda, carrega poucos passageiros. Chego na creche e a água escorre pelas paredes alagando a entrada. As crianças do berçário estão acordadas e duas delas me recebem com tapas e atiram brinquedos em mim. Tento vencer resistências e as abraço e beijo suas faces, e como que se tivesse conseguido decifrar gestos tão hostis, elas voltam e querem mais. A coordenadora fala que não quer mais o cargo e que propôs trabalhar em sala. A outra educadora que chega na porta diz que está solteira e que hoje quer sair. Depois me convida para vir no risoto que terá na creche, dizendo que é para eu ir comer galinha. Na outra sala, crianças acabam de acordar e a educadora me diz não estar bem hoje, pois brigou com o seu marido. Uma menina é esquecida cagada porque a educadora não percebeu, apesar de ela estar quieta em um canto (Diário de Campo, abril de 2004).

Um modo de escrever no qual o observador se inclui certamente causa estranhamento às modalidades mais impessoais e acadêmicas de escrita. $\mathrm{O}$ diário de campo se mostra assim como outro espaço de experimentação, que não se limita a transcrever ou representar a experiência do estágio. A escrita narrativa - e não somente descritiva - força o observador a implicar-se com o campo da experiência, tensionando-a com esse mesmo movimento. A escrita potencializa a produção de questões pertinentes ao 
estagiário, sendo essa uma das principais características de uma cognição enativa ${ }^{1}$ (Varela, Thompson \& Rosch, 2003), na qual o pensamento não é uma ação fora da corporalidade do sujeito, mas implica a consideração da experiência como constitutiva de toda forma de produção simbólica. O revivenciar a partir do escrever provoca uma nova configuração das questões da prática do estágio com as questões do próprio estagiário, podendo encontrar diálogo no espaço de supervisão como forma de esgaçar estas experiências, tendo em conta os limites da ação ética e da problematização da alteridade.

\section{OLHAR}

Em um tempo de capturas advindas do que poderíamos chamar de uma sobrevalorização do imaginário, pensar o olhar como ferramenta para um trabalho do psicólogo social é tanto pertinente quanto indicativo de perigo. Pertinente porque atentar para o olhar numa sociedade marcada pelas imagens é colocar em questão o estatuto do visível, na medida em que a produção de imagens através das novas tecnologias coloca uma nova dimensão para o imaginário e nossa capacidade de ver. Assim, indicar o modo de produção de visibilidades e atentar para o que escapa às imagens plásticas da tecnologia é ampliar as possibilidades dos visíveis. É também indicativo de perigo, porque olhar não é tarefa fácil, e com frequiência o que enxergamos não nos agrada e por vezes fazemos de conta que não o vemos, e mesmo crentes em nossa sabedoria, podemos cair facilmente em armadilhas imaginárias de promessas totalitárias. Mas o que está em jogo nesta ação de olhar que pode ser ferramenta para o trabalho?

Ao atentarmos para a ação do olhar, é importante salientar aqui as diferenças entre a prática comum da observação, encontrada nos mais diversos campos da Psicologia, e a conceituação do olhar como exercício de um observador. O olhar impõe considerar a posição do observador como implicado naquilo que observa. Considera ainda suas limitações como observador parcial e também determinado, abandonando a busca de uma realidade acessível objetivamente e passando a tomá-la como construída coletivamente (Varela, Thompson \& Rosch, 2003). Mas se o limite restringe, também possibilita. O olhar, como um modo de exercício de autoria, possibilita o reconhecimento ao

Termo inspirado na obra de Varela na qual a cognição é tomada não como uma representação de algo, mas como um processo que envolve a corporalidade do sujeito que conhece. distinguir objetos, situações ou suas nuanças que estavam invisíveis aos modos de viver recorrentes.

Assim, ao pensar nas diferenças entre o ver e o olhar apontadas por Cardoso (1989), o olhar exige do vidente muito mais implicação do que o simples ato de ver, que facilmente pavimenta as singularidades do campo de visão, produzindo uma saturação da imagem ao fechá-la para as brechas onde o olhar por vezes se detém. $\mathrm{O}$ ato de olhar atenta para as fraturas de uma suposta completude que o olho que vê não enxerga, e não toma o vidente e o visível como separados, mas coextensivos e necessários para a construção do olhar como produção de um sujeito em seu contato com aquilo que lhe é possível ver. Dessa forma, o olhar do psicólogo social encontrará percalços no caminho que testarão seus limites perceptivos. Enxergará facilmente teorias reificadas na prática e diagnósticos que produzem sintomas. Como também humano, corre o perigo de se achar possuidor de algum dom superior, e estará sempre na iminência de enxergar aquilo que seus limites ideais permitem, pois sua constituição imaginária também colore aquilo que se permite enxergar. Muitas vezes tomado da ânsia de ajudar e guiado por um ideal, atropela tantas coisas e deixa de observar as pequenas sutilezas das imagens, porque na imagem plástica - característica dos ideais - não cabem ranhuras e defeitos que um olhar atento consegue perceber.

Desejo. Desejo creches melhores, creches ideais que apareciam na minha mente e atrapalhavam minha visão das reais que tinha em frente. Desejo dos outros, daquelas mulheres e crianças mergulhadas em mal entendidos que fazem o sintoma gritar no corpo. Mal estar e angústia diante de situações de desânimo que já havia experimentado mas que me capturavam e imobilizavam, fazendo me questionar por onde andaria o interesse dessas educadoras. Medo. Medo de demandas vorazes que pareciam me engolir e ativavam meus fantasmas. Revolta. Revolta com palavras que machucam o corpo e se inscrevem muito mais que aquelas reproduzidas no mimeógrafo. Tristeza, com o debater das crianças sofrendo com um sintoma que remete na maioria das vezes a um desejo de amor. Ah, as educadoras também querem ser amadas, atendidas, ouvidas. Disputam e contam os minutos que fico em cada sala. Esperança, esperança que surge da resistência destas crianças, que sorriem diante de tantas dificuldades, que fazem sintoma, que batem, que gritam porque querem ser ouvidas, que abraçam, que beijam, que se aproximam, 
talvez porque saibam que o aprendizado passa pelo corpo (Diário de Campo, dezembro de 2003).

Há perigo no olhar impregnado por imagens plásticas sem história e buracos, que enxergam o mesmo até mesmo no mais estranho, como uma psicologia que reproduz as produções imaginárias das máquinas midiáticas, em uma tentativa de estabelecer um lugar imaginário e mais confortável para o exercício da profissão e adornamento do outro.

Não obstante, o olhar, marcado pelos percursos que faz, não é neutro e enxerga aquilo que pode ver. É um querer perceptivo balizado por quanto cada qual se permite ou suporta encarar as diferenças no outro que podem assim desestabilizar as representações, pois a visibilidade estará relacionada ao campo produzido entre cada olhar que se abre para o diferente e a visão de identidades reconhecidas no outro, tensionando a própria representação de si que está em jogo na relação especular. $\mathrm{Na}$ angústia produzida no encontro com uma diferença insuportável, o sujeito se utiliza muitas vezes do imaginário plástico para sobrepor imagens a alteridades, enxergando aquilo que consegue ver, a despeito do que possa aparecer em um olhar mais atento. Enfocando a dimensão política do ato do olhar, ele se coloca como parte da constituição do campo de pesquisa e intervenção, e ao tomá-lo como ação de atravessar a superfície especular do visível, como produtor de percurso visual ancorado nas suas experiências, está diretamente envolvido na produção de visibilidades dentro do jogo de forças das relações de poder estabelecidas dentro de determinada coletividade. Assim, o olhar como ferramenta não só possibilita uma estratégia de composição de novas visibilidades, mas também coloca em questão o lugar do vidente como suporte da experiência de tecer uma trajetória do olhar a partir do lugar que ocupamos. Isto pode ser pensado a partir do uso que o estagiário faz da sua posição de observação investida de legitimidade pela suposição de saber, o qual, em suas intervenções, cria campos de possíveis visibilidades, ao apontar para aquilo que muitas vezes não se quer ver. Claro que existirá sempre uma tensão entre estes visíveis e invisíveis dentro de uma instituição, e é por este motivo que a implicação política e ética do estagiário é de crucial importância nesse momento. Ao reconhecer a posição que ocupa e poder tensioná-la com os jogos de força e de verdade presentes nas instituições, estabelece condições de propiciar uma troca de pontos de observação. Neste sentido, a implicação política requer não tomar sua posição de observação como a verdadeira ou a que deve prevalecer, mas possibilitar que o tensionamento crie novas formas de configuração dentro da instituição, em que a intervenção assuma sua manifestação mais clara, sem com isso impor as concepções de mundo apenas do estagiário.

\section{PERCORRER}

O percurso se faz em uma trajetória que comporta deslocamentos e paradas. As paradas envolvem lugares e posições, e os deslocamentos, modos e obstáculos à passagem. Pensar o lugar é também pensar de onde partimos. A pergunta em relação ao lugar do qual falamos e dos lugares nos quais conseguimos transitar é um dos instrumentos de exercício do modo de psicologia social que assumimos. Uma freqüente discussão presente na rede de conversação das supervisões e tema provocativo para os estagiários, tal pergunta consistia em questionar os lugares que podemos ocupar como psicólogos - daqueles que estão postos, daqueles que necessitamos desconstruir e daqueles que temos que construir.

Percorrer e experimentar lugares torna-se ferramenta na medida em que passamos a nos perguntar sobre os lugares ocupados nos coletivos, o lugar que nós ocupamos enquanto psicólogos, fazendo nossas perguntas, nossas intervenções e acreditando estar ajudando; lugar do corpo que está junto da intervenção e fala em nós, e que coloca como questão a aproximação do outro, em encontros que podem ser produzidos se conseguimos abandonar todo o nosso manto de saber que nos impossibilita sentir o que está à volta.

A inquietação quanto ao lugar pode se constituir em um dispositivo para colocar em ação perguntas que devem estar sempre à mão para nos questionar se o que fazemos, não o fazemos apenas porque pensamos desde um certo lugar; se organizamos tudo à volta a partir desta centralidade; que apriorismos são depositados no meio circundante; qual o lugar do corpo que está junto no momento da intervenção, e qual sua afetação no que concerne à nossa implicação com o meio em que queremos de alguma forma intervir.

Essas questões exercem uma função de contraposição aos lugares imaginários que somos convocados a ocupar. A visibilidade das ferramentas de trabalho naturaliza a prática e organiza o espaço circundante em torno da posição central do sujeito detentor do saber, deixando escapar as possibilidades de uma nova configuração das relações pela cristalização da posição ocupada pelo psicólogo crente na estabilidade do seu lugar e na consistência 
imaginária $^{2}$ do seu trabalho. Isto ficou claro diante do lugar não instituído de psicólogo dentro das creches, onde, apesar de as pessoas ali presentes alimentarem demandas quando aos estagiários, ficava um pouco em suspenso o que se deveria fazer a partir desta posição. Apesar de o estagiário ser constantemente convocado a um lugar de saber e de ter possibilidades de assumir esta posição, com todas as facilidades e dificuldades implicadas, sua escolha foi por suspender estas posições e tentar desenvolver uma forma específica de habitar o lugar de estagiário, levando em consideração a singularidade do estagiário em questão e de sua forma peculiar de conseguir se aproximar do campo e poder construir uma intervenção ali.

Esta relação estabelecida com o lugar foi tema recorrente nas supervisões, e a partir da suspensão proposta nestes momentos, constituiu-se um operador importante para pensar a aproximação e inserção no campo, pois pensar o lugar remete não só à forma de se posicionar no espaço, mas também à forma como facilmente desconsideramos as sutilezas que o espaço proporciona como experiência subjetiva: lugar como ferramenta a nos perguntar constantemente que tipo de teleologia topológica estamos a criar para ordenar os espaços em que circulamos, constituindo classes e séries de condutas. Organizamos o mundo e o olhar que fazemos dele a partir da simbolização do lugar que ocupamos, pois nosso entendimento do mundo muitas vezes deixa de teorizar nosso próprio lugar, apesar de tomá-lo junto na delimitação daquilo que acreditamos constituir-se como realidade. Assumir a complexidade do lugar é aceitar a importância do lugar do observador como condição de possibilidade de qualquer simbolização e produção de conhecimento (Maturana, 2001). Se considerarmos que não podemos diferenciar uma ilusão de uma percepção no contexto da experiência, a posição do observador e a assunção de sua necessária existência como possibilidade para um conhecimento a partir de um certo lugar, nos implica em tomar nossa posição de observadores como parte crucial da experiência de conhecer o mundo.

Assim, nossas tentativas de explicação se referem ao lugar, à posição que ocupamos como observadores singulares, capazes de explicar nossas experiências a partir delas mesmas, em que a pergunta pelo nosso lugar é sempre pertinente. A implicação política desta dimensão topológica fica clara na medida em que a

2 Entendemos imaginário como uma experimentação subjetiva que convoca o corpo à totalidade e que está por este motivo ligado às relações especulares. Nosso entendimento contém uma influência importante de Lacan (1998). assunção do lugar como problema e ferramenta de trabalho coloca a implicação em primeiro plano e a determinação dos campos criados a partir daí em envolvimento direto com as estratégias de trabalho e posicionamentos éticos decorrentes de tal concepção.

O deslocar-se como parte do percorrer se refere aqui à possibilidade de poder viajar, entendida no sentido que Cardoso (1989) lhe dá ao indicar o distanciamento característico das viagens. Mas este deslocamento não se prende tanto ao espaço - em referência a uma sucessão de pontos com uma partida e uma chegada - mas faz referência ao tempo, na condição de um campo de presença onde a temporalidade é experimentada como uma diferenciação interna entre passado e futuro latentes no presente, e onde a experiência do distanciamento é sempre um distanciamento de si, na produção de um novo sentido. Assim, o deslocamento não necessita de uma distância extensa para poder operar, ele opera no sujeito mesmo, quando dado a viagens, na sua capacidade de distanciar-se de si mesmo e possibilitar a experiência do outro. Viajar é sempre conhecer-se a si mesmo de uma outra forma, é poder encontrar o estrangeiro nas coisas mais familiares, é estabelecer um estado de potência de estranhamento com as coisas à nossa volta, onde a experimentação do outro seja sempre a possibilidade de uma torção na representação de si mesmo, de criação.

O deslocamento é essencial no trabalho do psicólogo social, pois o coloca em condição de experimentar diferentes mundos e viagens às vezes bem perto de casa, e muitas vezes se questionar sobre sua própria morada e a morada de todos. É abertura à experiência da viagem no cotidiano, não como turista que procura o mesmo e o esperado nos lugares que encontra, mas como viajante, estrangeiro, na condição de poder se surpreender com o estranhamento de lugares distantes e próximos, na possibilidade de encontros engendrados pela abertura ao outro, na medida em que surge quando me deixo suspender em minha construção de meu lugar de morada.

Condição efetivamente ética, ao estabelecer como possibilidade uma morada coletiva, não determinada quanto aos modos de vida de cada um, mas como experimentação de uma existência estética em que o cuidado com a minha existência também é possibilidade de uma convivência e gestão desta convivência com outros. Psicologia social não como saber determinado a ditar formas de comportamento ou idealidades de convívio social, mas pequena tecnologia de relação possibilitadora de novos encontros e outras formas de perceber o mundo e a si mesmo. 


\section{UMA CAIXA DE FERRAMENTAS?}

Depois de apresentadas as ferramentas engendradas na experimentação desta psicologia em estágio, poderíamos pensar na imagem de uma caixa para carregá-las para os locais de intervenção. Mas esta imagem é aqui imprópria, pois ela leva a crer que poderíamos mantê-las como artefatos adjuntos ao nosso corpo, quando, pelo percurso mesmo deste artigo, tentamos mostrar que estas ferramentas são constitutivas do psicólogo, uma vez que operam como subjetivadoras de uma forma de estar e agir no mundo. Assim, a questão ética, tão ressaltada durante este texto, é entendida como a implicação de um ser-fazer considerado dentro de um coletivo em convivência, pois ela não se refere a regras de comportamento, mas sim, à forma de se constituir como sujeito ético, levando em consideração a coletividade da qual se faz parte, já que todo domínio de conhecimento está remetido à coletividade humana quando está em questão uma implicação ética. A questão política está intimamente ligada à ética no momento em que assumimos que o esclarecimento da implicação política de nossas ações já que não apelamos para objetos cristalizados que legitimam nossas posições de poder - aponta para a dimensão ética no sentido de colocar em pauta qual a forma de governo de si e dos outros que devemos levar em consideração quando trabalhamos com formas de subjetivação.

Dessa forma, pensar ferramentas para um psicólogo social, tendo em conta que elas são constitutivas do seu fazer, remete diretamente a essa questão, pois problematizar as condições em que se produzem os conhecimentos deste campo de saber e a implicação política de suas ações indica necessariamente um posicionamento quanto à formação e ação dentro de um coletivo. Esta proposta de estágio busca, assim, colocar em questão estas implicações no momento de formação dos psicólogos, pois não deixa de ser uma aposta política nas possibilidades de transformação de uma intervenção ética e política. É uma proposta política de transformação que abarca, no mesmo processo, a angústia da perda de margens seguras e a euforia de novos portos de chegada.

\section{REFERÊNCIAS}

Baptista, L. A. S. (2000). A Fábrica de interiores: a formação psi em questão. Niterói: EdUFF.

Cardoso, S. (1989). O olhar viajante (do etnólogo). Em A. Novaes (Org.), $O$ olhar. (pp. 347-360). São Paulo: Companhia das Letras.

Castel, R. (1998). As metamorfoses da questão social: uma crônica do salário. Petrópolis: Vozes.

Foucault, M. (1994). História da sexualidade. Rio de Janeiro: Graal.

Ibáñes, T. (1993). La dimnesión política de la psicología social. Revista Latinoamericana de Psicología, 25(1), 1934.

Lacan, J. M. E. (1998). Escritos. Rio de Janeiro: Jorge Zahar.

Latour, B. (2004). Redes que a razão desconhece: laboratórios, bibliotecas, coleções. Em A. Parente. Tramas da Rede. (pp.39-63). Porto Alegre: Sulina.

Maraschin, C. \& Tittoni, J. (2002). Cotidiano e configuração de espaços de aprendizagem. Educar em Revista, 19, 147157.

Maturana, H. (2001). Cognição, ciência e vida cotidiana. Belo Horizonte: Editora da UFMG.

Paparelli, R. B. (2005). Psicólogos em formação: vivências e demandas em plantão psicológico. Tese de Doutorado Não-Publicada. Programa de Pós-Graduação em Ciências, Secretaria da Saúde do Estado de São Paulo, São Paulo.

Varela, F. J., Thompson, E. \& Rosch, (2003). A mente incorporada: ciências cognitivas e experiência humana. Porto Alegre: Artmed.

Scisleski, A. C. C., Maraschin, C. \& Tittoni, J. (2006). A psicologia social e o trabalho em comunidades: limites e possibilidades. Revista Interamericana de Psicologia, 40(1) 47-54.

Silva, R. N. (2004). Notas para uma genealogia da psicologia social. Psicologia \& Sociedade, 16(2), 12-19.

Silva, L A.V., Oliveira, R. F.\& Franco, A. L. S. (1998). Inserção do psicólogo em programas de atenção primária à adolescência: uma experiência em Salvador. Psicologia: Reflexão e Crítica, 11(3,n.esp), 605-20.

Recebido em 20/01/2006 Aceito em 18/04/2006

Endereço para correspondência: Rafael Diehl. Rua Ramiro Barcelos, 2600 sala 201d, Santa Cecília, CEP 90035003, Porto Alegre-RS. E-mail: diehlrafael@yahoo.com.br 